\title{
Apoptosis induced in MCF-7 human breast cancer cells by 2',4'-dihydroxy-6-methoxy-3,5-dimethylchalcone isolated from Eugenia aquea Burm f. leaves
}

\author{
ANAS SUBARNAS ${ }^{1}$, AJENG DIANTINI $^{1}$, RIZKY ABDULAH ${ }^{1,2}$, ADE ZUHROTUN $^{3}$, YUNI E. HADISAPUTRI ${ }^{4}$, \\ IRMA M. PUSPITASARI ${ }^{1,2}$, CHIHO YAMAZAKI ${ }^{2}$, HIROYUKI KUWANO $^{4}$ and HIROSHI KOYAMA ${ }^{2}$ \\ ${ }^{1}$ Department of Pharmacology and Clinical Pharmacy, Faculty of Pharmacy, Universitas Padjadjaran, Jatinangor, West Java, \\ Indonesia; ${ }^{2}$ Department of Public Health, Gunma University Graduate School of Medicine, Maebashi, Gunma, Japan; \\ ${ }^{3}$ Department of Biological Pharmacy, Faculty of Pharmacy, Universitas Padjadjaran, Jatinangor, West Java, Indonesia; \\ ${ }^{4}$ Department of General Surgical Science, Gunma University Graduate School of Medicine, Maebashi, Gunma, Japan
}

Received April 18,2014; Accepted January 29, 2015

DOI: $10.3892 / 01.2015 .2981$

\begin{abstract}
During a previous study that aimed to identify anticancer agents within primate-consumed plants, the present group identified that Eugenia aquea (E. aquea) possessed potential as a source of anticancer agents. The ethanol extract of E. aquea leaves exhibited strong inhibitory activity against the proliferation of the human breast adenocarcinoma MCF-7 cell line. The inhibition of proliferation was determined using an MTT assay. The present study was performed to isolate the active compound within the E. aquea leaves that generated the aforementioned activity, and resulted in the isolation of 2',4'-dihydroxy-6-methoxy-3,5-dimethylchalcone, which was identified through the analysis of spectroscopic data. This compound was examined for its inhibitory activity against the MCF-7 cell line using a MTT assay, and the ability of 2',4'-dihydroxy-6-methoxy-3,5-dimethylchalcone to induce apoptosis through the activation of the poly(adenosine diphosphate-ribose) polymerase (PARP) protein was also investigated. The results of the present study revealed that the isolated compound inhibited cell proliferation in a dose-dependent manner, possessed an $\mathrm{IC}_{50}$ of $74.5 \mu \mathrm{g} / \mathrm{ml}(250 \mu \mathrm{M})$ and promoted apoptosis via the activation of PARP. It was concluded that these results indicated a requirement for additional investigations into 2',4'-dihydroxy-6-methoxy-3,5-dimethylchalcone in order to
\end{abstract}

Correspondence to: Professor Anas Subarnas, Department of Pharmacology and Clinical Pharmacy, Faculty of Pharmacy, Universitas Padjadjaran, Jalan Raya Bandung-Sumedang Km 21, Jatinangor, West Java 45363, Indonesia

E-mail: aasubarnas@yahoo.co.id

Key words: Eugenia aquea, primates, cancer, apoptosis provide a basis for the use of this compound in the management of cancer.

\section{Introduction}

Breast cancer is a type of cancer that accounts for $>1.2$ million new cases worldwide and 500,000 mortalities annually, resulting in breast cancer being the most malignant form of cancer among females (1). Numerous clinically-used drugs are available for the treatment of cancer, including breast cancer, but the use of these agents does not provide optimum effectiveness for the treatment of the disease. The majority of the drugs result in serious side-effects, which generates excessive damage to normal cells (2). Therefore, investigating anti-cancer drugs of plant origin continues to provide novel and significant possibilities for anti-cancer agents. Numerous types of bioactive compounds from medicinal plants have been isolated at present and several of these compounds are currently undergoing further investigation (3-5).

Plants consumed by primates are considered to be a promising source of therapeutic agents for the management of human diseases, including cancer (6). Previous investigations have been performed on primate-consumed plants to assess their anti-tumor activity (6). Additional investigations led to the isolation of kaempferol-3- $O$-rhamnoside from the leaves of Schima wallichii Korth, a plant commonly consumed by primates. Kaempferol-3-O-rhamnoside exhibited inhibitory activity against MCF-7 breast cancer cell proliferation through the activation of the caspase cascade pathway (7). In another study, 42 species of primate-consumed plants that grow in Indonesia were evaluated for their antiproliferative activity against MCF-7 human breast cell lines using a MTT bioassay. The results revealed that certain plant extracts demonstrated strong inhibitory activity against MCF-7 cell proliferation, and one of these was the extract from the leaves of Eugenia aquea (E. aquea) (8). The present study aimed to identify the active compound derived from the leaves of E. aquea, responsible for the antiproliferative activity against MCF-7 cell lines, and to examine the pro-apoptotic activity of this compound. 


\section{Materials and methods}

Plant materials. The leaves of E. aquea were collected from Pangandaran Beach Conservation Area (Pangandaran, West Java, Indonesia). The plant species was then confirmed by the Department of Biology of Padjadjaran University (Bandung, West Java, Indonesia). The leaves were dried in the open air, away from direct sunlight.

Cell culture and treatment. MCF-7 human breast cancer cell lines were purchased from the American Type Culture Collection (Manassas, VA, USA). The cell lines were cultured in RPMI-1640 medium (Sigma-Aldrich, St. Louis, MO, USA) supplemented with $10 \%$ fetal bovine serum and antibiotics, which consisted of $100 \mathrm{units} / \mathrm{ml}$ penicillin and $100 \mu \mathrm{g} / \mathrm{ml}$ streptomycin. For the cell treatments, various concentrations of the sample were added to the cell culture medium. After $24 \mathrm{~h}$, the cells were released from treatment, the medium was replaced and the cells were subsequently collected at 24 and $48 \mathrm{~h}$.

Drug sensitivity assays. Cell proliferation analysis was performed using a MTT assay on cells in the presence of various concentrations of 2',4'-dihydroxy-6-methoxy-3,5-dimethylchalcone isolated from Eugenia aquea at various concentrations ranged from $3-1342 \mu \mathrm{M}$, according to the method described by Abdulah et al (9). Briefly, $2 \times 10^{4}$ cells per $50 \mu \mathrm{l} /$ well were plated into 96 -well plates. Subsequent to the initial cell seeding, various concentrations of primate-consumed plant extracts were added and the cells were incubated for $24 \mathrm{~h}$. In total, $10 \mu \mathrm{l}$ WST-8 assay cell-counting solution (Dojindo Molecular Technologies, Inc., Kumamoto, Japan) was added to each well and incubated at $37^{\circ} \mathrm{C}$ for $3 \mathrm{~h}$. Following the addition of $100 \mu \mathrm{l} /$ well of $1 \mathrm{M} \mathrm{HCl}$, the cell proliferation rate was determined by measuring absorbance at a wavelength of $450 \mathrm{~nm}$. The absorbance was read using a microtiter plate reader (BD Biosciences, Franklin Lakes, NJ, USA).

Extraction and isolation. A total of $736 \mathrm{~g}$ of dried leaves of E. aquea were powdered and extracted using $95 \%$ ethanol $(3 \times 24 \mathrm{~h})$ at room temperature and the solvent was evaporated under reduced pressure at $50^{\circ} \mathrm{C}$ to yield concentrated extracts. The concentrated extracts were partitioned using a mixture of $n$-hexane-water (3:1) to yield hexane and water layers. The water layer was further extracted using ethyl acetate to yield ethyl acetate and water fractions. The $n$-hexane and ethyl acetate fractions demonstrated inhibitory activity against the proliferation of MCF-7 cells. The $n$-hexane fraction was subsequently subjected to column chromatography over silica gel and eluted with $n$-hexane-ethyl acetate mixtures of increasing polarity ( $n$-hexane to ethyl acetate, 9:1, 8:2, $7: 3,6: 4$ and 5:5) to yield seven fractions. Fraction four was repeatedly further purified via silica gel column chromatography, with the elution of $n$-hexane-ethyl acetate mixtures of increasing polarity, resulting in the isolation of $150.30 \mathrm{mg}$ of a pure active compound, in the form of yellow crystals. The compound was identified using an analysis of its spectroscopic data, consisting of ultraviolet (UV), infrared (IR), mass and nuclear magnetic resonance (NMR) spectra.
Cell extraction and western blot analysis. Protein concentrations were determined using a bicinchoninic acid protein assay kit (Pierce Biotechnology, Inc., Rockford, IL, USA). In total, $40 \mu \mathrm{g}$ protein was electrophoresed on a Mini-PROTEAN TGX Precast Gel (4-20\%; Bio-Rad Laboratories, Hercules, CA, USA) and electro-transferred to a $7 \times 8 \mathrm{~cm}$ Hybond enhanced chemiluminescence membrane (GE Healthcare Life Sciences, Little Chalfont, UK). Apoptosis-associated proteins were analyzed by immunoblot analysis using poly(adenosine diphosphate-ribose) polymerase (PARP) and Akt antibodies at a 1:1,000 dilution (Cell Signaling Technology, Danvers, MA, USA). $\beta$-actin (Sigma-Aldrich) served as the loading control.

\section{Results}

Determination of the structure of 2',4'-dihydroxy-6-methoxy-3,5-dimethylchalcone. The active compound 2',4'-dihyd roxy-6-methoxy-3,5-dimethylchalcone was isolated from the leaves of E. aquea as an active compound that demonstrated inhibitory activity against the proliferation of MCF-7 cells. The compound exhibited strong yellow color, with a melting point of $125-126^{\circ} \mathrm{C}$ and a molecular ion peak at $\mathrm{m} / \mathrm{z} 298$ in the electron ionization mass spectrum. The molecular ion peak and ${ }^{1} \mathrm{H}$ and ${ }^{13} \mathrm{C}$ NMR data indicated that this compound possessed a molecular formula of $\mathrm{C}_{18} \mathrm{H}_{18} \mathrm{O}_{4}$.

The UV spectrum exhibited a major absorption band at $\lambda_{\max } 338 \mathrm{~nm}$, indicating $\mathrm{MeOH}$, and a minor band at $\lambda_{\max } 225 \mathrm{~nm}$, which are characteristic for a type of flavonoids with a structural skeleton of chalcone (10). This hypothesis was supported by the color reaction, which revealed the color of this compound to be red-orange in the presence of $\mathrm{NaOH}$. The IR spectrum indicated the presence of hydroxyl (3304 $\left.\mathrm{cm}^{-}\right)$, conjugated carbonyl $\left(1628 \mathrm{~cm}^{-}\right)$, and aromatic (1606-1545 $\left.\mathrm{cm}^{-}\right)$groups in the molecule, which also supported this hypothesis.

The 'HNMR spectrumof 2',4'-dihydroxy-6-methoxy-3,5-dimethylchalcone revealed signals at $\delta 7.82(1 \mathrm{H} ; d ; J=18.0 \mathrm{~Hz})$ and $\delta 8.03(1 \mathrm{H} ; d ; J=18.0 \mathrm{~Hz})$, which is characteristic for the $\alpha$ and $\beta$ protons of the $\mathrm{O}=\mathrm{C}-\mathrm{C}=\mathrm{C}$-benzene group of a chalcone skeleton (Fig. 1) (10). Furthermore, proton signals appeared at $\delta 7.43(3 \mathrm{H} ; m)$ and $\delta 7.71(2 \mathrm{H} ; d d ; J=6.0$ and $12.0 \mathrm{~Hz})$, which were assumed to result from aromatic hydrogens of the 1-substituted benzene ring, and at $\delta 13.82(1 \mathrm{H} ; s)$, which was derived from a hydrogen of the hydroxyl group in the benzene ring chelated to a carbonyl group. The ${ }^{1} \mathrm{H}$ NMR spectrum demonstrating signals at the downfield region is shown in Fig. 1, and indicated that the compound may have possessed a 1,2,3,4,5,6-substituted benzene ring A and a 1-substituted benzene ring $\mathrm{B}$, with each of the rings being termed the $\mathrm{A}$ - and B-rings on the left and right of the chalcone skeleton, respectively. In addition, the ${ }^{1} \mathrm{H}$ NMR spectrum exhibited two singlet signals at $\delta 2.10(3 \mathrm{H} ; s)$ and $2.15(3 \mathrm{H} ; s)$, revealing two hydrogens belonging to methyl groups that are attached to a benzene ring, and one methoxyl signal at $\delta 3.67(3 \mathrm{H} ; s)$. These data indicated that the A-ring of this chalcone may be substituted with two methyl, one methoxyl and two hydroxyl groups.

The ${ }^{13} \mathrm{C}$ NMR spectrum identified the presence of 18 carbons, three of which were oxyaryl carbons revealed by the signals at $\delta 159.77,161.76$ and 163.20. These carbon signals indicated the presence of oxygenation in the chalcone skeleton. 


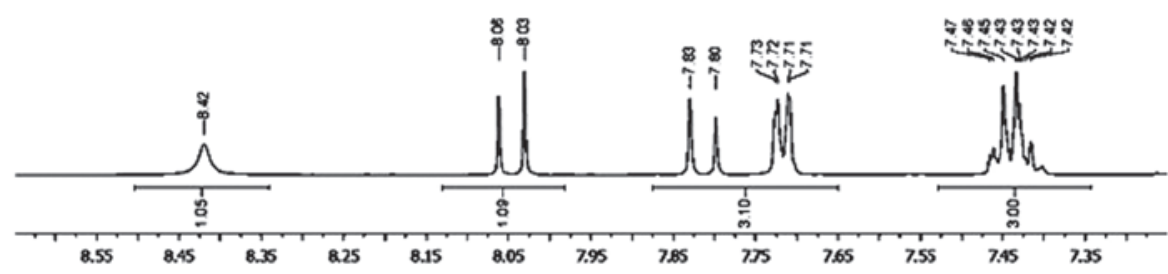

Figure 1. 'H nuclear magnetic resonance profile of 2',4'-dihydroxy-6-methoxy-3,5-dimethylchalcone, obtained from the leaves of Eugenia aquea.

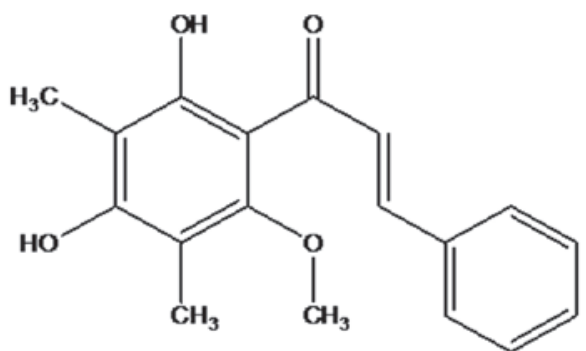

Figure 2.Structure of 2',4'-dihydroxy-6-methoxy-3,5-dimethylchalcone.

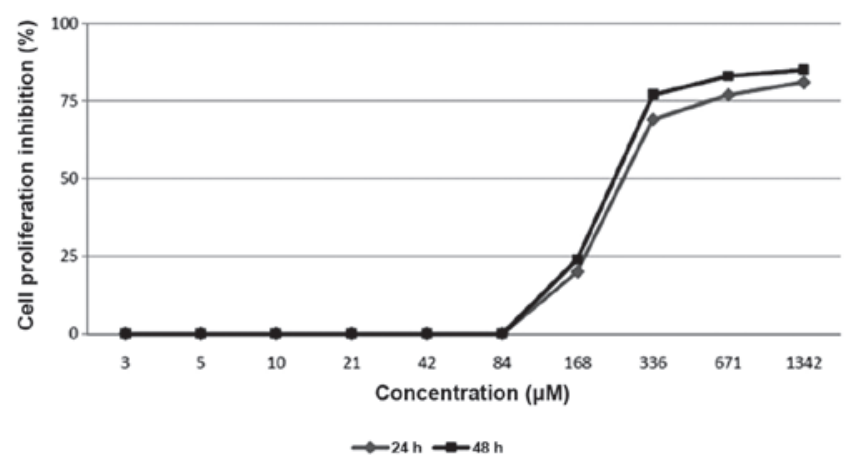

Figure 3. Effect of treatment with 2',4'-dihydroxy-6-methoxy-3,5-dimethylchalcone for 24 and $48 \mathrm{~h}$ on the proliferation of MCF-7 breast cancer cells.

\section{2',4'-dihydroxy-6-methoxy-3,5-dimethylchalcone}

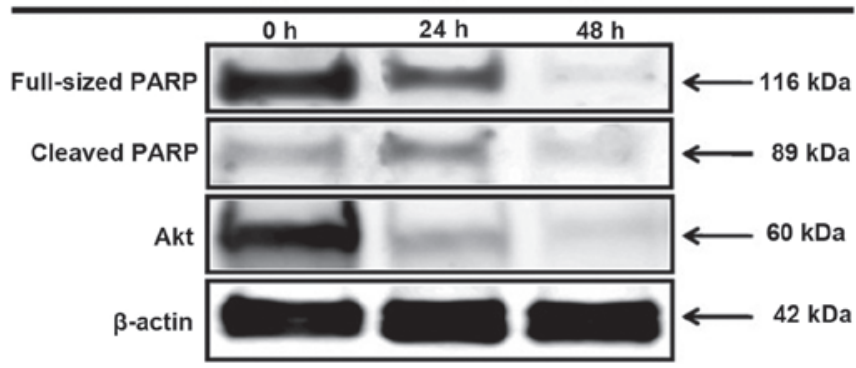

Figure 4. Western blot analysis of the protein expression of poly(adenosine diphosphate-ribose) polymerase (PARP), an apoptotic marker, and Akt, a survival signaling protein, in MCF-7 cells treated for $24 \mathrm{~h}$ with 2',4'-dihydroxy-6-methoxy-3,5-dimethylchalcone.

The existence of a conjugated carbonyl group was indicated by the appearance of the signal at $\delta 193.70$. The ${ }^{13} \mathrm{C}$ NMR data supported the assumption of the substitution pattern of this chalcone compound.

The position of the oxygen groups was determined by analysis of the ${ }^{1} \mathrm{H}$ multiplicity bond connectivity (HMBC) data. As indicated in the ${ }^{1} \mathrm{H}$ NMR spectrum, the chalcone skeleton of 2',4'-dihydroxy-6-methoxy-3,5-dimethylchalcone may possess a hydroxyl group chelated to a carbonyl group, indicating that the hydroxyl group was attached to C-6' of the A-ring. In the HMBC spectrum, a correlation was observed between the proton signal of the hydroxyl group at $\delta 13.82$ and carbon signals at $\delta 107.93\left(\mathrm{C}^{-} 3^{\prime}\right)$ and $109.04\left(\mathrm{C}-1^{\prime}\right)$. The proton signal of one methyl group at $\delta 2.10$ correlated with the carbon signals at $\delta 163.70\left(\mathrm{C}^{-} 6^{\prime}\right)$ and $161.76\left(\mathrm{C}^{\prime} 4^{\prime}\right)$, whereas the signal of another methyl group at $\delta 2.15$ correlated with the carbon signals at $\delta 161.76\left(\mathrm{C}-4^{\prime}\right)$ and $159.77\left(\mathrm{C}-2^{\prime}\right)$. These indicated that two methyl groups were attached to $\mathrm{C}-3^{\prime}$ and $\mathrm{C}-5^{\prime}$, and two oxygen functions were present at C-2' and C-4'. Furthermore, the proton signal of methoxyl group at $\delta 3.67$ correlated with the carbon signal at $\delta 159.77\left(\mathrm{C}-2^{\prime}\right)$, indicating that this compound possessed a methoxyl group at C-2' and a hydroxyl group at C-4'.

Thus, from the aforementioned accumulated data, the compound was identified as 2',4'-dihydroxy-6-methoxy-3,5-dimethylchalcone (Fig. 2), which was confirmed by comparison of its spectral data with the reported data (11).

Inhibitory activity of 2',4'-dihydroxy-6-methoxy-3,5-dimethylchalcone against the proliferation of MCF-7 cells. The present study evaluated 2',4'-dihydroxy-6-methoxy-3,5-dimethylchalcone for its effect on the proliferation of MCF-7 breast cancer cell lines using an MTT assay. The evaluation resulted in a dose-dependent manner inhibition of the compound on the cell proliferation (Fig. 3). The compound was revealed to strongly inhibit the proliferation of the MCF-7 cell line in the examinations at 24 and $48 \mathrm{~h}$, demonstrating $\mathrm{IC}_{50}$ values of $270 \mu \mathrm{M}$ and $250 \mu \mathrm{M}$, respectively.

Proapoptotic activity of 2',4'-dihydroxy-6-methoxy-3,5-dimethylchalcone mediated through PARP protein activation. The MTT assay revealed the strong inhibitory activity of 2',4'-dihydroxy-6-methoxy-3,5-dimethylchalcone against the proliferation of MCF-7 cells. Therefore, the compound was further examined for its proapoptotic activity through PARP protein activation within 24 and $48 \mathrm{~h}$ of treatment. As can be observed in Fig. 5, the present study provides evidence that the inhibition of the proliferation of MCF-7 human breast cancer cells caused by 2',4'-dihydroxy-6-methoxy-3',5'-dimethylchalone was mediated by the induction of apoptosis, marked by PARP protein activation, which is one of the best biomarkers of apoptosis. Furthermore, 2',4'-dihydroxy-6-methoxy-3',5'-dimethylchalone also inhibited the expression of Akt, the protein that signals cell survival (Fig. 4). 


\section{Discussion}

Searching for anticancer agents on the basis of following up plants used by primates is an innovative approach that possesses high potential for developing novel anticancer drugs or lead compounds from primate-consumed plants. In a previous study, it was reported that the extracts of plants ingested by primates demonstrated strong cytotoxicity in the MCF-7 breast cancer cell line, and the extract from E. aquea leaves demonstrated potential as an agent requiring further investigation (8).

The leaves of E. aquea, also known as watery rose apple or 'jambu air' in Indonesia, are a food that is usually consumed by non-human primates in the Pangandaran Beach Primate Conservation Area of West Java, Indonesia (8).

The present study aimed to identify a cytotoxic compound within the leaves of $E$. aquea, which led to the isolation of 2',4'-dihydroxy-6-methoxy-3,5-dimethylchalcone. This compound demonstrated a dose-dependent inhibition of the growth of MCF-7 cells. This evidence was in agreement with the findings of previous studies $(12,13)$. In addition, the same compound, 2',4'-dihydroxy-6-methoxy-3,5-dimethylchalcone, isolated from the buds of Cleistocalyx operculatus significantly inhibits the growth of human liver cancer SMMC-7721 cells and is able to induce apoptosis of SMMC-7721 cells in vitro (12). This compound also exerts antitumor effects in vivo on a solid human tumor xenograft mouse model, using human liver cancer SMMC-7721 cells (13). Potential hepatoprotective effects, which may be associated with the attenuation of oxidative stress, accelerating the antioxidant cascade and inhibition of lipid peroxidation, have also been demonstrated by 2',4'-dihydroxy-6-methoxy-3,5-dimethylchalcone (14).

In the present study, 2',4'-dihydroxy-6-methoxy-3,5-dimethylchalcone was also found to induce the apoptosis of MCF-7 cells, as indicated by the changes in the expression levels of PARP, which were analyzed within 24 and $48 \mathrm{~h}$ of treatment. The $\mathrm{N}$-terminal fragment of PARP, a 89-kDa peptide that is cleaved from the $116 \mathrm{kDa}$ full-length PARP protein, was detected in MCF-7 cells as early as $24 \mathrm{~h}$ subsequent to treatment with 2',4'-dihydroxy-6-methoxy-3,5-dimethylchalcone. In addition, as one of the most important survival signaling pathways in malignancy, Akt plays a significant role in determining the chemosensitivity of cancer cells. The survival signaling proteins were decreased in the MCF-7 cells by treatment with 2',4'-dihydroxy-6-methoxy-3,5-dimethylchalcone, as demonstrated by the reduced expression of the Akt protein.

In conclusion, the present results indicate that 2',4'-dihydroxy-6-methoxy-3,5-dimethylchalcone inhibited the growth of MCF-7 cells through the induction of apoptosis and downregulation of the Akt pathway. Additional studies are required to evaluate the toxicity and determine detailed mechanisms of the antiproliferative action of 2',4'-dihydroxy-6-methoxy-3,5-dimethylchalcone to provide a scientific basis for the chemopreventive and chemotherapeutic application of 2',4'-dihydroxy-6-methoxy-3,5-dimethylchalcone for the management of breast cancer.

\section{Acknowledgements}

This study was supported by The Directorate General of Higher Education of The Ministry of Education and Culture of Indonesia (Grand-in-Aid for The International Research Collaborations and Publications, grant no. 430/SP2H/PP/ DP2M/VII/2010).

\section{References}

1. Ferlay J, Shin HR, Bray F, Forman D, Mathers C and Parkin DM: Estimates of worldwide burden of cancer in 2008: GLOBOCAN 2008. Int J Cancer 127: 2893-2917, 2010.

2. Sakarkar DM and Deshmukh VN: Ethnopharmacological review of traditional medicinal plants for anticancer activity. Int J Pharm Tech Res 3: 298-308, 2011.

3. Kinghorn AD, Farnsworth NR, Soejarto DD, et al: Novel strategies for the discovery of plant-derived anticancer agents. Pure Appl Chem 71: 1611-1618, 1999.

4. Kinghorn AD: The role of pharmacognosy in modern medicine. Expert Opin Pharmacother 3: 77-79, 2002.

5. Kinghorn AD, Farnsworth NR, Soejarto DD, et al: Novel strategies for the discovery of plant-derived anticancer agents. Pharm Biol 41 (Suppl 1): S53-S67, 2003.

6. Koshimizu K, Murakami A, Hayashi H, Ohigashi H, Subarnas A, Gurmaya KJ and Ali A: Biological activities of edible and medicinal plants from Indonesia and Malaysia. In: Proceedings of The Tokyo International Forum on Conservation and Sustainable Use of Tropical Bioresources, Tokyo, pp203-208, 1998.

7. Diantini A, Subarnas A, Lestari K, Halimah E, et al: Kaempferol-3-O-rhamnoside isolated from the leaves of Schima wallichii Korth. inhibits MCF-7 breast cancer cell proliferation through activation of the caspase cascade pathway. Oncol Lett 3: 1069-1072, 2012.

8. Subarnas A, Diantini A, Abdulah R, Zuhrotun A, Yamazaki C, Nakazawa $M$ and Koyama H: Antiproliferative activity of primates-consumed plants against MCF-7 human breast cancer cell lines. E3 J Med Res 1: 38-43, 2012.

9. Abdulah R, Faried A, Kobayashi K, Yamazaki C, Suradji EW, Ito K, Suzuki K, Murakami M, Kuwano H and Koyama H: Selenium enrichment of broccoli sprout extract increases chemosensitivity and apoptosis of LNCaP prostate cancer cells. BMC Cancer 9: 414, 2009.

10. Marby TJ, Markham KR and Thomas MB (eds): The Determination and Interpretation of NMR Spectra of Flavonoids. In: The systematic identification of flavonoids. Springer-Verlag, New York, pp253-273, 1970.

11. Amor EC, Villaseñor IM, Yasin A and Choudhary MI: Prolyl endopeptidase inhibitors from Syzygium samarangense (Blume) Merr. \& L. M. Perry. Z Naturforsch C 59: 86-92, 2004.

12. Ye CL, Liu JW, Wei DZ, Lu YH and Qian F: In vitro anti-tumor activity of 2',4'-dihydroxy-6'-methoxy-3',5'-dimethylchalcone against six established human cancer cell lines. Pharmacol Res 50: 505-510, 2004.

13. Ye CL, Liu JW, Wei DZ, Lu YH and Qian F: In vivo antitumor activity by 2',4'-dihydroxy-6'-methoxy-3',5'-dimethylchalcone in a solid human carcinoma xenograft model. Cancer Chemother Pharmacol 56: 70-74, 2005.

14. Yu WG, Qian J and Lu YH: Hepatoprotective effects of 2',4'-dihydroxy-6'-methoxy-3',5'-dimethylchalcone on CCl4-induced acute liver injury in mice. J Agric Food Chem 59: 12821-12829, 2011. 